\title{
Inverse association between central obesity and arterial stiffness in Korean subjects with metabolic syndrome: a cross-sectional cohort study
}

Ki-Bum Won ${ }^{1,2}$, Hyuk-Jae Chang ${ }^{1,3^{*}}$, Hiroyuki Niinuma ${ }^{2}$, Koichiro Niwa ${ }^{2}, K_{\text {Kyewon Jeon }}^{3}$, In-Jeong Cho ${ }^{1}$, Chi-Young Shim ${ }^{1}$, Geu-Ru Hong ${ }^{1}$ and Namsik Chung ${ }^{1}$

\section{Abstract}

Background: Metabolic syndrome (MetS) is associated with increased risks of diabetes and atherosclerotic cardiovascular disease. Whether central obesity $(\mathrm{CeO})$ is a prerequisite for the diagnosis of MetS in the International Diabetes Federation (IDF) definition is a substantial issue because it may influence the clinical value of MetS for predicting subclinical atherosclerosis.

Methods: We investigated the relation between MetS, as defined by the National Cholesterol Education ProgramAdult Treatment Panel (NCEP-ATP) III criteria, and arterial stiffness according to CeO status in 2,560 healthy Korean subjects who participated in a community-based cohort study. Arterial stiffness was measured using brachial-ankle pulse wave velocity (baPWV).

Results: The prevalence of MetS was 37\%; 84\% of MetS subjects had CeO. The prevalence of diabetes was significantly higher in MetS subjects than in non-MetS subjects (30 vs. 8\%, $\mathrm{p}<0.001$ ). The number of MetS components was significantly correlated with baPWV $(r=0.311, p<0.001)$. In a subgroup analysis of MetS subjects, the prevalence of diabetes was not significantly different in MetS subjects with and without CeO. MetS subjects without $\mathrm{CeO}$ had significantly higher baPWV than those with $\mathrm{CeO}(1654 \pm 315$ vs. $1578 \pm 270 \mathrm{~cm} / \mathrm{s}, \mathrm{p}=0.002)$. Multiple regression models revealed that waist circumference was independently associated with decreased baPWV in MetS subjects.

Conclusions: Despite the significant correlation between the number of MetS components and arterial stiffness, there appeared to be an inverse association between $\mathrm{CeO}$ and arterial stiffness in MetS subjects. In contrast to the IDF definition, our findings suggest that $\mathrm{CeO}$ is not crucial for the diagnosis of MetS in otherwise healthy Koreans having multiple metabolic risk factors with respect to subclinical atherosclerosis reflected in arterial stiffness.

Keywords: Metabolic syndrome, Central obesity, Pulse wave velocity

\footnotetext{
* Correspondence: hjchang@yuhs.ac

'Division of Cardiology, Yonsei Cardiovascular Center, Yonsei University

College of Medicine, 50 Yonsei-ro, Seodaemungu, Seoul 120-752, Republic of

Korea

${ }^{3}$ Severance Biomedical Science Institute, Seoul, Republic of Korea

Full list of author information is available at the end of the article
} 


\section{Background}

Metabolic syndrome (MetS) is associated with increased risks of diabetes and atherosclerotic cardiovascular disease (CVD) [1-3]. The prevalence of MetS is rapidly increasing worldwide $[4,5]$, and the diagnosis of MetS is important to identify individuals at high risk for CVD because MetS is strongly associated with the development of atherosclerotic major cardiovascular (CV) events [6,7]. Although the pathogenesis of MetS related to its individual components is complex, central obesity (CeO) has been considered to be a causative factor of MetS because it is a predominant component of MetS $[8,9]$. Especially, the International Diabetes Federation (IDF) suggests that $\mathrm{CeO}$, defined by waist circumference with ethnicity-specific values, is essential for the diagnosis of MetS [10]. However, subjects without $\mathrm{CeO}$ but with multiple metabolic abnormalities are not diagnosed with MetS according to the IDF definition.

MetS is a concept that focuses attention on a constellation of complex, multifactorial health problems for the prevention of CVD. Although obesity is one of the important risk factors for the development of CVD [11,12], several recent studies have reported the phenomenon of the "obesity paradox" in which obesity is associated with improved prognoses in patients after the development of CVD, including acute myocardial infarction (AMI) and heart failure [13-16]. These results may imply that, in a healthy population, the primary prevention of CVD might be more important in non-obese individuals with multiple CV risk factors. Thus, it is important to identify the significance of MetS diagnosis in subjects without $\mathrm{CeO}$ with respect to subclinical atherosclerosis in a relatively healthy population without a previous history of major CV events.

Arterial stiffness is an important surrogate marker of subclinical atherosclerosis, and increasing arterial stiffness represents an increased risk for major adverse $\mathrm{CV}$ events $[17,18]$. Brachial-ankle pulse wave velocity (baPWV) is a reproducible index of arterial elasticity and stiffness [19]. Although a previous study reported that MetS is associated with increased arterial stiffness [20], the association between MetS and arterial stiffness according to CeO status is unknown. Thus, the present study investigated the relation between MetS and arterial stiffness according to the presence of $\mathrm{CeO}$ in relatively healthy Korean subjects who participated in health examinations for a communitybased cohort study.

\section{Methods}

This is a cross-sectional investigation analyzing data collected for a prospective cohort study. We used the data of 2,560 subjects who participated in baseline health examinations for a community-based cohort study in the Seoul area between April 2010 and November 2012.
Subjects with a previous history of CVD, cerebrovascular disease, or malignancy were not included in the present study according to the study protocol.

All blood samples were obtained after an 8-hr fast and analyzed for glucose, triglycerides, high-density lipoprotein (HDL) cholesterol, and low-density lipoprotein (LDL) cholesterol. Weight, height, and waist circumference were measured while subjects wore light clothing and no shoes. Waist circumference was measured at the midpoint between the iliac crest and the lower border of the rib cage. Body mass index (BMI) was calculated as weight $(\mathrm{kg}) \div$ height $\left(\mathrm{m}^{2}\right)$. Diabetes was defined as either fasting glucose $\geq 126 \mathrm{mg} / \mathrm{dL}$, a referral diagnosis of diabetes, or antidiabetic treatment. MetS was defined as the presence of 3 or more of the following components, based on the National Cholesterol Education ProgramAdult Treatment Panel (NCEP-ATP) III definition [1]: (a) $\mathrm{CeO}$ based on waist circumference $\geq 90 \mathrm{~cm}$ in males or $\geq 80 \mathrm{~cm}$ in females in accordance with the Asia Pacific World Health Organization guidelines; (b) HDL cholesterol $<40 \mathrm{mg} / \mathrm{dL}$ in males or $<50 \mathrm{mg} / \mathrm{dL}$ in females; (c) triglycerides $\geq 150 \mathrm{mg} / \mathrm{dL}$; (d) systolic blood pressure (SBP) $\geq 130 \mathrm{mmHg}$ or diastolic blood pressure (DBP) $\geq 85 \mathrm{mmHg}$ or on antihypertensive treatment; and (e) impaired fasting glucose, defined as fasting glucose $\geq 100 \mathrm{mg} / \mathrm{dL}$, or antidiabetic treatment.

All subjects abstained from caffeine-containing food for at least 45 minutes before the measurement of baPWV. After all subjects had been resting in the supine position for at least 5 minutes in a quiet room, blood pressure and baPWV were measured using an automated waveform analyzer (Colin VP-2000, Colin Medical Instruments Corp., Komaki, Japan). Pneumatic cuffs were wrapped around both upper arms and ankles and connected to a plethysmographic sensor to determine the volume pulse waveform. The highest value of baPWV measured on either side of each patient was used for analysis. This study was approved by the local ethics committee of our institution, and informed consent was obtained from each participant.

\section{Statistical analysis}

Continuous variables are expressed as mean \pm SD or medians and interquartile range according to the distribution. Categorical variables are presented as percentages. Continuous variables were compared using independent t-test or Mann-Whitney U-test, and categorical variables were compared using the $\chi^{2}$ test or Fisher's exact test, as appropriate. Correlational analysis between the number of MetS components and baPWV was performed using Pearson's correlation test. After identifying the differences in baPWV according to the presence of MetS, the mean value of baPWV was compared in subjects with MetS according to their $\mathrm{CeO}$ status. Univariate 
linear regression analysis was performed to evaluate the association between $\mathrm{CeO}$ and baPWV in subjects with MetS. Multiple regression models were analyzed to identify the independent association between $\mathrm{CeO}$ and baPWV after consecutive adjustment for confounding risk factors, including age, gender, smoking, heart rate, serum creatinine, number of MetS components, and other MetS components in subjects with MetS. Multiple linear regression analysis for identifying the association between baPWV and CV risk factors was performed in subjects with MetS. The forced entry method was used to enter independent variables into the multiple regression models. SPSS version 18 (SPSS Inc., Chicago, IL, USA) was used for all statistical analyses. All statistical tests were 2 -tailed, and $\mathrm{p}<0.05$ was considered significant.

\section{Results}

A flowchart of this study is presented in Figure 1. The clinical characteristics of the 2,560 participants (60 \pm 8 years, 33\% men) in this study are shown in Table 1. The prevalence of MetS was 37\%; 84\% of subjects with MetS had $\mathrm{CeO}$ that satisfied the IDF definition. The incidence of $\mathrm{CeO}$ was significantly higher in subjects with MetS than in those without MetS ( 84 vs. 37\%, p <0.001) (Figure 2). The prevalence of diabetes was significantly higher in subjects with MetS than in those without MetS (30 vs. $8 \%, \mathrm{p}<0.001$ ). The number of MetS components was significantly correlated with baPWV $(r=0.311$, $\mathrm{p}<0.001$ ) (Figure 3).

Among the subjects with MetS, the prevalence of diabetes was not significantly different between MetS subjects with and without $\mathrm{CeO}$. The incidence of current medications for the treatment of hypertension, dyslipidemia, and diabetes was not significantly different between MetS subjects with and without $\mathrm{CeO}$. However, the incidence of male gender (62 vs. $32 \%, \mathrm{p}<0.001)$ and smoking (52 vs. $29 \%, \mathrm{p}<0.001$ ) was significantly higher in MetS subjects without $\mathrm{CeO}$ than in those with $\mathrm{CeO}$. MetS subjects without $\mathrm{CeO}$ had significantly higher baPWV than those with $\mathrm{CeO}(1654 \pm 315$ vs. $1578 \pm$ $270 \mathrm{~cm} / \mathrm{s}, \mathrm{p}=0.002$ ) (Figure 4).

Multiple linear regression models were performed to identify the association between $\mathrm{CeO}$ and baPWV in subjects with MetS. Unadjusted linear regression analysis showed an inverse association between central obesity and baPWV in subjects with MetS $(B=-76.001$, $\mathrm{p}<0.001)$. This inverse association persisted after consecutive adjustment for confounding risk factors: age $(\mathrm{B}=-88.328, \mathrm{p}<0.001)$; age and gender $(\mathrm{B}=-85.560$, $\mathrm{p}<0.001)$; age, gender, and smoking $(\mathrm{B}=-85.537, \mathrm{p}<$ $0.001)$; age, gender, smoking, and heart rate $(B=-70.866$, $\mathrm{p}=0.001)$; age, gender, smoking, heart rate, and serum creatinine $(\mathrm{B}=-70.392, \mathrm{p}=0.002)$; age, gender, smoking, heart rate, serum creatinine, and number of MetS components $(B=-78.961, p=0.001)$; and age, gender, smoking, heart rate, LDL, eGFR, number of MetS components, and other MetS components $(\mathrm{B}=-84.231, \mathrm{p}=0.001)$ (Table 2).

Multiple linear regression analysis to identify the association between baPWV and CV risk factors was performed in subjects with MetS. Waist circumference $(\mathrm{B}=$ -4.536, $\mathrm{p}<0.001)$, age $(\mathrm{B}=15.973, \mathrm{p}<0.001)$, heart rate $(\mathrm{B}=6.425, \mathrm{p}<0.001)$, fasting glucose $(\mathrm{B}=0.648, \mathrm{p}=$ $0.021)$, and SBP $(B=9.166, p<0.001)$ were independently associated with baPWV in subjects with MetS (Table 3).

\section{Discussion}

To the best of our knowledge, the present study provides the first information on the inverse association between $\mathrm{CeO}$ and arterial stiffness in MetS subjects among a relatively healthy Korean population without major adverse CV events. In addition, we identified the prevalence of diabetes was not significantly different in MetS

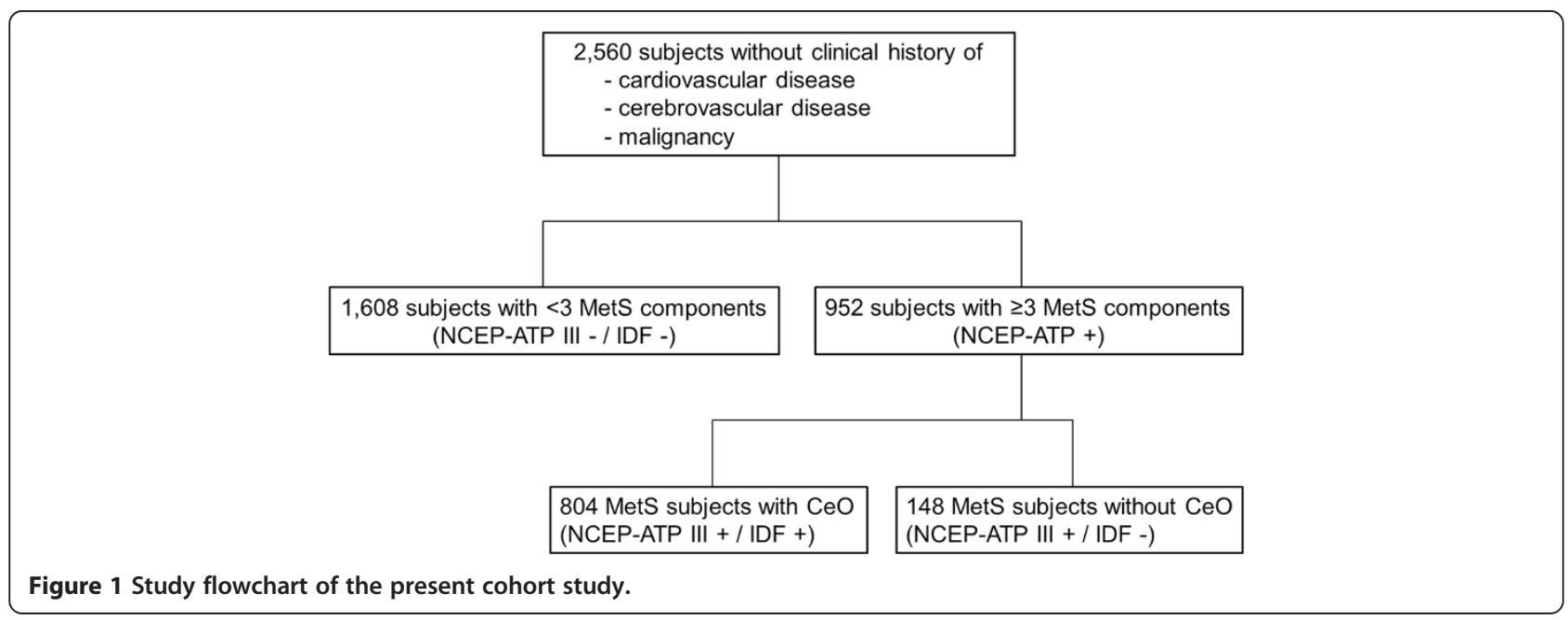


Table 1 Baseline characteristics

\begin{tabular}{|c|c|c|c|c|c|}
\hline \multirow[t]{2}{*}{ Characteristics } & \multirow{2}{*}{$\begin{array}{l}\text { No MetS (NCEP- } \\
\text { ATP III - / IDF -) } \\
(\mathrm{n}=1,608)\end{array}$} & \multicolumn{3}{|c|}{ MetS (NCEP-ATP III +) } & \multirow[t]{2}{*}{$\mathbf{P}$} \\
\hline & & Total $(n=952)$ & With $\mathrm{CeO}($ IDF +$)(n=804)$ & Without $\mathrm{CeO}$ (IDF -) $(n=148)$ & \\
\hline Age (years) & $65(60,69)$ & $64(57,69)$ & $62 \pm 8$ & $61 \pm 7$ & $<0.001$ \\
\hline Male gender (\%) & 31 & 36 & 32 & $62^{*}$ & 0.004 \\
\hline Smoking (\%) & 24 & 32 & 29 & $52^{*}$ & $<0.001$ \\
\hline $\mathrm{BMI}\left(\mathrm{kg} / \mathrm{m}^{2}\right)$ & $24.0 \pm 2.7$ & $26.4 \pm 2.9$ & $26.8 \pm 2.8$ & $23.9 \pm 1.9^{*}$ & $<0.001$ \\
\hline Waist circumference $(\mathrm{cm})$ & $81 \pm 8$ & $89 \pm 7$ & $90 \pm 7$ & $81 \pm 6^{*}$ & $<0.001$ \\
\hline Heart rate (bpm) & $66 \pm 9$ & $68 \pm 10$ & $68 \pm 10$ & $70 \pm 11^{\dagger}$ & $<0.001$ \\
\hline $\mathrm{SBP}(\mathrm{mmHg})$ & $120 \pm 14$ & $128 \pm 15$ & $128 \pm 15$ & $130 \pm 15$ & $<0.001$ \\
\hline $\mathrm{DBP}(\mathrm{mmHg})$ & $72 \pm 9$ & $77 \pm 10$ & $76 \pm 10$ & $79 \pm 10^{\dagger}$ & $<0.001$ \\
\hline Antihypertensive medications (\%) & 29 & 66 & 67 & 66 & $<0.001$ \\
\hline Total cholesterol (mg/dL) & $201 \pm 36$ & $197 \pm 37$ & $197 \pm 37$ & $195 \pm 36$ & 0.006 \\
\hline Triglycerides (mg/dL) & $94(71,118)$ & $136(103,186)$ & $164 \pm 82$ & $210 \pm 80^{*}$ & $<0.001$ \\
\hline HDL cholesterol (mg/dL) & $57(51,63)$ & $45(37,55)$ & $47 \pm 13$ & $41 \pm 11^{*}$ & $<0.001$ \\
\hline LDL cholesterol (mg/dL) & $110(83,127)$ & $106(83,130)$ & $121 \pm 34$ & $117 \pm 33$ & 0.096 \\
\hline Lipid lowering medications (\%) & 27 & 31 & 31 & 27 & 0.034 \\
\hline Creatinine (mg/dL) & $0.78(0.63,0.95)$ & $0.81(0.68,0.93)$ & $0.79 \pm 0.19$ & $0.87 \pm 0.19^{*}$ & $<0.001$ \\
\hline Fasting glucose (mg/dL) & $121(105,137)$ & $125(108,143)$ & $109 \pm 24$ & $114 \pm 27^{\ddagger}$ & $<0.001$ \\
\hline Diabetes (\%) & 8 & 30 & 30 & 30 & $<0.001$ \\
\hline Antidiabetic treatment (\%) & 7 & 25 & 82 & 84 & $<0.001$ \\
\hline Duration of diabetes (months) & $92(44,202)$ & $92(44,152)$ & $110 \pm 85$ & $107 \pm 87$ & 0.177 \\
\hline baPWV (cm/s) & $1576(1414,1760)$ & $1625(1452,1864)$ & $1578 \pm 270$ & $1654 \pm 315^{\dagger}$ & $<0.001$ \\
\hline
\end{tabular}

Continuous variables are expressed as mean $\pm S D$ or median [interquartile]. Categorical variables are presented as percentages. baPWV, brachial-ankle pulse wave velocity; $B M I$, body mass index; $C e O$, central obesity; $D B P$, diastolic blood pressure; $H D L$, high-density lipoprotein; IDF, International Diabetes Federation; $L D L$, low-density lipoprotein; MetS, metabolic syndrome; NCEP-ATP III, National Cholesterol Education Program-Adult Treatment Panel III; SBP, systolic blood pressure. ${ }^{*} p<0.001$ vs. NCEP-ATP III + / IDF $+{ }^{\dagger} p<0.01$ vs. NCEP-ATP III + / IDF + ${ }^{\neq} p<0.05$ vs. NCEP-ATP III + / IDF +.

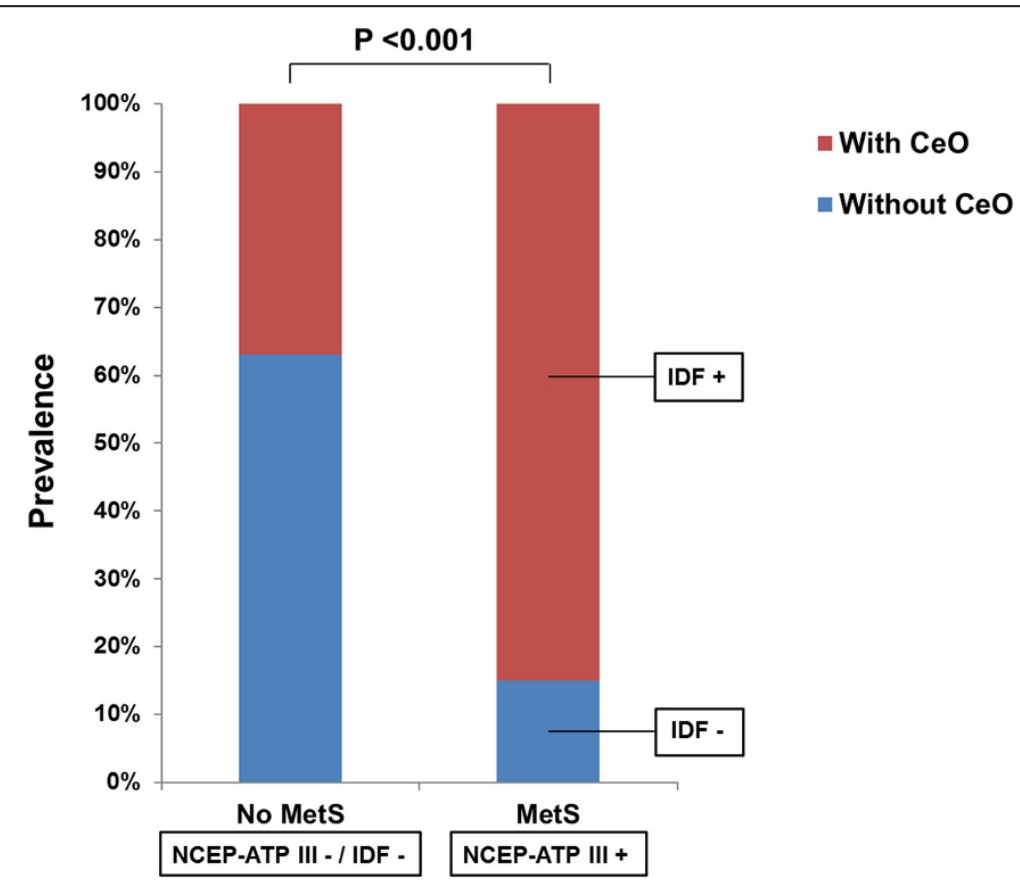

Figure 2 Incidence of $\mathrm{CeO}$ in subjects with and without MetS. 


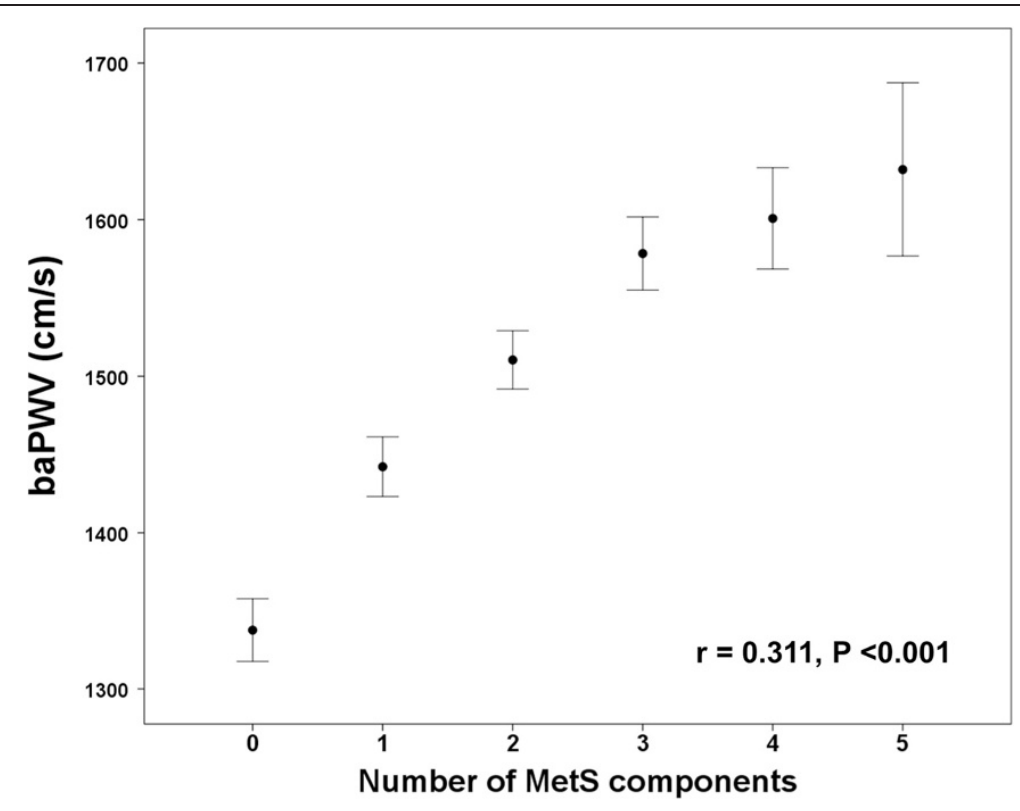

Figure 3 Correlation between the number of MetS components and baPWV. The error bars represent the standard deviation.

subjects according to their $\mathrm{CeO}$ status. It might be reasonable to diagnose MetS based on the number of metabolic abnormalities considering the significant correlation between the number of MetS components and the progression of subclinical atherosclerosis that was reflected in arterial stiffness. However, in contrast with the IDF definition, our results indicate that the diagnosis of MetS should be necessary in subjects without $\mathrm{CeO}$ but with multiple metabolic risk factors with respect to subclinical atherosclerosis reflected in arterial stiffness in the general population.

MetS is a concept that focuses attention on complex multifactorial health problems for the prevention of CVD. The prevalence of MetS is rapidly increasing worldwide, and it affects approximately $31 \%$ of adults in Korea [21]. This simultaneous clustering of metabolic abnormalities appears to confer a substantial additional $\mathrm{CV}$ risk over and above the sum of the risk associated with each

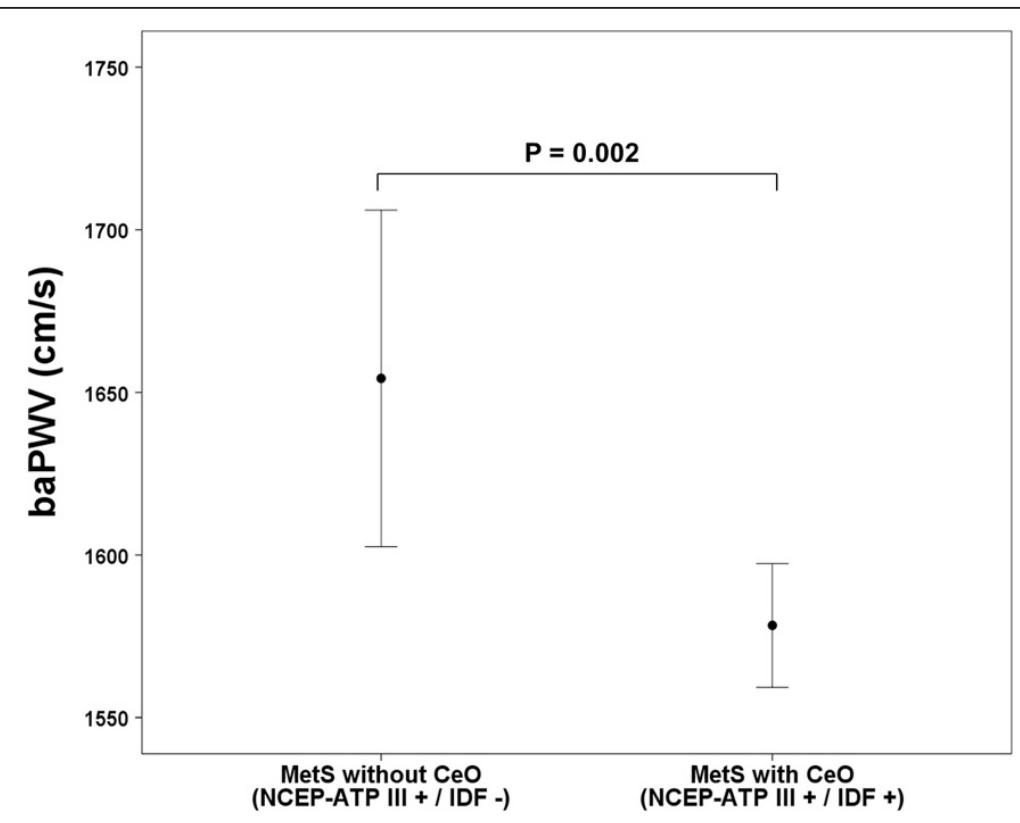

Figure 4 Comparison of baPWV in subjects with MetS according to $\mathrm{CeO}$ status. The error bars represent the standard deviation. 
Table 2 Multiple regression models for identifying the association between central obesity and baPWV in subjects with MetS

\begin{tabular}{lccccc}
\hline & \multicolumn{5}{c}{ baPWV } \\
\cline { 2 - 6 } & $\mathbf{R}^{\mathbf{2}}$ & $\mathbf{B}$ & $\mathbf{S E}$ & $\boldsymbol{\beta}$ & $\mathbf{P}$ \\
\hline MetS with CeO & & & & & \\
Model 1 & 0.010 & -76.001 & 24.842 & -0.099 & $<0.001$ \\
Model 2 & 0.191 & -88.328 & 22.480 & -0.115 & $<0.001$ \\
Model 3 & 0.191 & -85.560 & 23.077 & -0.111 & $<0.001$ \\
Model 4 & 0.191 & -85.537 & 23.090 & -0.111 & $<0.001$ \\
Model 5 & 0.257 & -70.866 & 22.208 & -0.092 & 0.001 \\
Model 6 & 0.258 & -70.392 & 22.207 & -0.091 & 0.002 \\
Model 7 & 0.260 & -78.961 & 22.741 & -0.103 & 0.001 \\
Model 8 & 0.285 & -84.231 & 25.272 & -0.109 & 0.001 \\
\hline B, standadizd
\end{tabular}

$\beta$, standardized coefficients; $B$, unstandardized coefficients; baPWV, brachialankle pulse wave velocity; $\mathrm{CeO}$, central obesity; LDL, low-density lipoprotein; MetS, metabolic syndrome; SE, standard error.

"Other MetS components" refer to the dichotomous variables of HDL cholesterol, triglycerides, blood pressure, and fasting glucose according to the NCEP-ATP III criteria.

Model 1: Unadjusted.

Model 2: Adjusted for age.

Model 3: Adjusted for age and male gender.

Model 4: Adjusted for age, male gender, and smoking.

Model 5: Adjusted for age, male gender, smoking, and heart rate.

Model 6: Adjusted for age, male gender, smoking, heart rate, and

serum creatinine.

Model 7: Adjusted for age, male gender, smoking, heart rate, serum creatinine, and number of MetS components.

Model 8: Adjusted for age, male gender, smoking, heart rate, serum creatinine, number of MetS components, and other MetS components.

Table 3 Multiple linear regression analysis for identifying the association between baPWV and CV risk factors in subjects with MetS

\begin{tabular}{lcccc}
\hline & \multicolumn{4}{c}{ baPWV } \\
\cline { 2 - 5 } & B & SE & $\boldsymbol{\beta}$ & $\mathbf{P}$ \\
\hline $\mathrm{R}^{2}=0.508$ & & & & \\
Waist circumference & -4.536 & 1.025 & -0.117 & $<0.001$ \\
Age & 15.973 & 0.911 & 0.429 & $<0.001$ \\
Male gender & -15.440 & 25.512 & -0.027 & 0.545 \\
Smoking & 18.800 & 22.330 & 0.032 & 0.400 \\
Heart rate & 6.425 & 0.683 & 0.229 & $<0.001$ \\
Serum creatinine & 66.219 & 44.050 & 0.046 & 0.133 \\
Number of MetS components & 2.052 & 11.565 & 0.005 & 0.859 \\
Triglycerides & 0.115 & 0.089 & 0.034 & 0.198 \\
HDL cholesterol & 0.707 & 0.599 & 0.032 & 0.238 \\
Fasting glucose & 0.648 & 0.281 & 0.057 & 0.021 \\
SBP & 9.166 & 0.644 & 0.494 & $<0.001$ \\
DBP & 0.169 & 1.031 & 0.006 & 0.870 \\
\hline B, standardized coeffients B, unstany & & &
\end{tabular}

$\beta$, standardized coefficients; $B$, unstandardized coefficients; baPWV, brachialankle pulse wave velocity; $D B P$, diastolic blood pressure; $H D L$, high-density ipoprotein; MetS, metabolic syndrome; $S B P$, systolic blood pressure; $S E_{\text {, }}$ standard error. individual abnormality [22,23]. Thus, MetS has been promoted as a means for identifying the risk of CVD development in clinical practice. Although the pathogenesis of MetS related to the individual components is not well understood, $\mathrm{CeO}$ has been considered to have a pivotal role in the pathogenesis of MetS [8,9]. In particular, compared with other definitions of MetS, the IDF criteria defined $\mathrm{CeO}$ as a prerequisite for the diagnosis of MetS [10]. However, individuals without $\mathrm{CeO}$ but having multiple metabolic abnormalities are not diagnosed with MetS according to the IDF definition. Because this may influence the clinical usefulness of MetS for the prevention of CVD, it is an important issue whether $\mathrm{CeO}$ is a prerequisite for the diagnosis of MetS.

Arterial stiffness is a significant surrogate marker of subclinical atherosclerosis, and increasing arterial stiffness is independently associated with an increased risk for major adverse CV events $[17,18]$. Although previous studies reported that MetS is strongly associated with subclinical atherosclerosis [20,24], the relation between MetS and subclinical atherosclerosis according to the presence of $\mathrm{CeO}$ has not been evaluated. In this study, we evaluated the correlation between the number of MetS components and arterial stiffness. Then, we compared the arterial stiffness in subjects with MetS defined by NCEP-ATP III criteria according to their $\mathrm{CeO}$ status. Interestingly, despite the significant correlation between the number of MetS components and arterial stiffness, MetS subjects without $\mathrm{CeO}$ had significantly increased arterial stiffness compared to those with $\mathrm{CeO}$. This inverse association persisted after adjusting for confounding $\mathrm{CV}$ risk factors including other MetS components. Considering these results, it might be reasonable to diagnose MetS based solely on the number of metabolic risk factors, but the diagnosis of MetS might be even more important in subjects without $\mathrm{CeO}$ but with multiple metabolic risk factors in order to identify individuals at high risk for CVD. The IDF definition may be helpful for understanding the pathogenesis of MetS because this definition primarily focuses on the predominant characteristic of MetS, but it is uncertain whether the IDF definition is more efficient for predicting subclinical atherosclerosis in the general population compared to other definitions of MetS. The results of our study might raise an important question as to whether $\mathrm{CeO}$ should be a prerequisite component for the diagnosis of MetS for the prevention of CVD in the general population.

Clinical features of atypical MetS subjects who are not accompanied by $\mathrm{CeO}$ have not been well known, especially in Asian populations. Most definitions of MetS are reasonable, in that the criteria for metabolic abnormalities used to identify individuals with MetS differ according to gender and ethnicity. However, other lifestyle factors strongly related to the development of CVD such 
as smoking status are not considered in the definition of MetS. The relation between smoking and obesity is not completely understood, but previous numerous crosssectional studies have reported that body weight or BMI is lower in smokers than in nonsmokers [25-29]. Moreover, smokers weighed less than nonsmokers, and body leanness increased with the duration of smoking in the second National Health and Nutrition Examination Survey study [30]. Although these studies did not evaluate the association between smoking and $\mathrm{CeO}$, smoking might have a suppressive effect on $\mathrm{CeO}$ considering the close association among anthropometric indices including body weight, BMI, and waist circumference. In the present study, while the incidence of smoking was significantly higher in subjects with MetS than in those without MetS, MetS subjects without $\mathrm{CeO}$ had significantly higher incidence of smoking than those with $\mathrm{CeO}$. Considering these results, further investigation to identify the impact of smoking on MetS and its individual components may be necessary.

Although obesity is significantly associated with the development of CVD [11,12], an interesting phenomenon known as the "obesity paradox" has been reported in patients after the development of CVD. Several studies reported either an inverse linear or U-shaped association between BMI and all-cause mortality in patients with heart failure [31-33]. This association was also replicated in patients after the event of AMI [15,16,34]. The exact mechanism by which obesity may improve prognoses in patients with heart failure or AMI is unknown. Moreover, the impact of $\mathrm{CeO}$ on prognoses in patients with major CV complications has not been evaluated despite the significant relationships among anthropometric indices. However, considering this paradoxical phenomenon, is note worthy that the primary prevention of major CVD may need to be emphasized more in high-risk, otherwise healthy, non-obese subjects who have no previous history of major adverse CV events. Recently, the World Health Organization (WHO) strongly recommended that the concept of MetS should be applied in subjects without established CVD [35]. This communitybased cohort study was performed in subjects who had no previous history of CVD, cerebrovascular disease, or malignancy. We identified the clinical features of atypical MetS subjects who did not have $\mathrm{CeO}$ compared to the typical MetS subjects with $\mathrm{CeO}$, and found that the IDF definition had a major limitation for predicting subclinical atherosclerosis compared to the NCEP-ATP III definition in the present study.

MetS has been promoted as a means of identifying the risk for type 2 diabetes development. While the pathogenesis of MetS is not well understood, $\mathrm{CeO}$ and insulin resistance are acknowledged as important causative factors for the development of MetS [8-10]. It is obvious that $\mathrm{CeO}$ is strongly associated with insulin resistance. However, despite the substantial increase in the prevalence of MetS and type 2 diabetes in Asian population, the clinical features of type 2 diabetes in Asia are distinctly different from the features of type 2 diabetes in other parts of the world; it develops in a much shorter time, at a younger age, and in subjects with much lower BMI in Asia [36]. In addition, several studies on the pathogenesis of type 2 diabetes in Korean subjects reported that impaired insulin secretion was more prominent than insulin resistance, even in people with impaired glucose tolerance $[37,38]$. In the present study, the incidence of $\mathrm{CeO}$ was significantly higher in subjects with MetS than in those without MetS, and $\mathrm{CeO}$ was a predominant characteristics in subjects with MetS. Additionally, the prevalence of diabetes was significantly higher in subjects with MetS than in those without MetS. However, there was no significant difference in the prevalence of diabetes according to the presence of $\mathrm{CeO}$ among the MetS subjects. Accordingly, it may be that $\mathrm{CeO}$ is not an essential component for the diagnosis of MetS with respect to the identification of the risk for type 2 diabetes development in Asian populations. Considering that the fasting glucose level was significantly higher in MetS subjects without $\mathrm{CeO}$ than in those with $\mathrm{CeO}$, and that fasting glucose was independently associated with increased baPWV in subjects with MetS, diabetes might have been less well controlled in MetS subjects without $\mathrm{CeO}$ than in those with $\mathrm{CeO}$ in this cohort study.

A number of previous studies have reported an inverse association between obesity and arterial stiffness in youth or middle age [39-41]. However, there is a paucity of data on this inverse association in an older population. Here, we identified an inverse association between $\mathrm{CeO}$ and arterial stiffness in relatively older subjects with MetS. Considering the results of a recent study that showed different component clusters of MetS revealed varying associations with arterial stiffness [42], our findings may provide substantial information on the association between individual MetS components and subclinical atherosclerosis in an older general population.

This study has some limitations. First, although the criteria of MetS might be dependent on ethnicity [43], the present study included only a Korean population. However, this might be a unique point for identifying the limitation of the IDF definition for predicting subclinical atherosclerosis in Asian population. Second, the impact of MetS on the progression of subclinical atherosclerosis might differ somewhat according to age group [44]. However, no sub-analysis according to age group was performed because the participants in this cohort study were relatively older. Third, several previous studies of Korean population reported that men had higher 
baPWV values compared with women $[45,46]$. In the present study, the incidence of male gender was significantly higher in MetS subjects without $\mathrm{CeO}$ than in those with $\mathrm{CeO}$, and this may be a clinical characteristic of atypical MetS subjects who do not have $\mathrm{CeO}$. Although we identified an inverse association between $\mathrm{CeO}$ and baPWV in MetS subjects after adjusting for gender differences, further investigations are necessary to identify the impact of gender on this inverse association. Lastly, although the incidence of current medications for the treatment of hypertension, dyslipidemia, and diabetes was not significantly different between MetS subjects with and without $\mathrm{CeO}$, we could not eliminate the possible effects of underlying medications on subclinical atherosclerosis because of the observational design of this study. Further large prospective studies are required to address these issues.

\section{Conclusion}

An inverse association between $\mathrm{CeO}$ and arterial stiffness was observed in MetS subjects among relatively healthy Korean populations. This association persisted after adjusting for confounding CV risk factors. Moreover, the prevalence of diabetes was not significantly different in MetS subjects with and without $\mathrm{CeO}$. In contrast to the IDF definition, the diagnosis of MetS may be important in Korean subjects without $\mathrm{CeO}$ but having multiple metabolic risk factors.

\section{Abbreviations}

AMI: Acute myocardial infarction; BMI: Body mass index; baPWB Brachial-ankle pulse wave velocity; CeO: Central obesity; CV: Cardiovascular: CVD: Cardiovascular disease; DBP: Diastolic blood pressure; HDL: High-density lipoprotein; IDF: International Diabetes Federation; LDL: Low-density lipoprotein; MetS: Metabolic syndrome; NCEP-ATP: National Cholesterol Education Program-Adult Treatment Panel; SBP: Systolic blood pressure: WHO: World Health Organization.

\section{Competing interests}

The authors declare that they have no competing interests.

\section{Authors' contributions}

All the authors listed in the manuscript participated in the design of the study and writing of the manuscript. KW and HC performed the statistical analysis. All the authors read and approved the final manuscript.

\section{Acknowledgment}

This research was supported by the Leading Foreign Research Institute Recruitment Program through the National Research Foundation of Korea, funded by the Ministry of Education, Science and Technology (2012027176).

\section{Author details}

'Division of Cardiology, Yonsei Cardiovascular Center, Yonsei University College of Medicine, 50 Yonsei-ro, Seodaemungu, Seoul 120-752, Republic of Korea. ${ }^{2}$ Division of Cardiology, St. Luke's International Hospital, Tokyo, Japan. ${ }^{3}$ Severance Biomedical Science Institute, Seoul, Republic of Korea.

Received: 3 July 2014 Accepted: 9 January 2015

Published: 27 January 2015

\section{References}

1. NCEP. Executive summary of the third report of the national cholesterol education program (NCEP) expert panel on detection, evaluation, and treatment of high blood cholesterol in adults (adult treatment panel III). JAMA. 2001;285:2486-97.

2. Grundy SM, Cleeman Jl, Daniels SR, Donato KA, Eckel RH, Franklin BA, et al. Diagnosis and management of the metabolic syndrome: an American Heart Association/National Heart, Lung, and Blood Institute Scientific Statement. Circulation. 2005;112:2735-52.

3. Alberti KG, Zimmet P, Shaw J. The metabolic syndrome-a new worldwide definition. Lancet. 2005;366:1059-62.

4. Mozumdar A, Liguori G. Persistent increase of prevalence of metabolic syndrome among U.S. adults: NHANES III to NHANES 1999-2006. Diabetes Care. 2011:34:216-9.

5. Nestel P, Lyu R, Low LP, Sheu WH, Nitiyanant W, Saito I, et al. Metabolic syndrome: recent prevalence in East and Southeast Asian populations. Asia Pac J Clin Nutr. 2007:16:362-7.

6. Klein $B E$, Klein $R$, Lee KE. Components of the metabolic syndrome and risk of cardiovascular disease and diabetes in beaver Dam. Diabetes Care. 2002;25:1790-4.

7. Nakanishi N, Takatorige T, Fukuda H, Shirai K, Li W, Okamoto M, et al. Components of the metabolic syndrome as predictors of cardiovascular disease and type 2 diabetes in middle-aged Japanese men. Diabetes Res Clin Pract. 2004;64:59-70

8. Anderson PJ, Critchley JA, Chan JC, Cockram CS, Lee ZS, Thomas GN, et al. Factor analysis of the metabolic syndrome: obesity vs insulin resistance as the central abnormality. Int J Obes Relat Disord. 2001;25:1782-8.

9. Carr DB, Utzschneider KM, Hull RL, Kodama K, Retzlaff BM, Brunzell JD, et al. Intra-abdominal fat is a major determinant of the National Cholesterol Education Program Adult Treatment Panel III criteria for the metabolic syndrome. Diabetes. 2004;53:2087-94.

10. Alberti KG, Zimmet P, Shaw J. Metabolic syndrome-a new world-wide definition. A Consensus Statement from the International Diabetes Federation. Diabet Med. 2006:23:469-80.

11. Calle EE, Thun MJ, Petrelli JM, Rodriguez C, Heath Jr CW. Body mass index and mortality in a prospective cohort of US adults. N Engl J Med. 1999;341:1097-105.

12. Peeters A, Barendregt JJ, Willekens F, Mackenbach JP, Al Mamun A, Bonneux L. Obesity in adulthood and its consequences for life expectancy: a life-table analysis. Ann Intern Med. 2003;138:24-32.

13. Horwich TB, Fonaraow GC, Hamilton MA, MacLellan WR, Woo MA, Tillisch $\mathrm{JH}$. The relationship between obesity and mortality in patients with heart failure. J Am Coll Cardiol. 2001;38:789-95.

14. Morse SA, Gulati R, Reisin E. The obesity paradox and cardiovascular disease. Curr Hypertens Rep. 2010;12:120-6.

15. Bucholz EM, Rathore SS, Reid KJ, Jones PG, Chan PS, Rich MW, et al. Body mass index and mortality in acute myocardial infarction patients. Am J Med. 2012;125:796-803.

16. Lundergan CF, Ross AM, McCarthy WF, Reiner JS, Boyle D, Fink C, et al. Predictors of left ventricular function after acute myocardial infarction: effects of time to treatment, patency, and body mass index. Am Heart J. 2001;142:43-50.

17. Yamashina A, Tomiyama H, Arai T, Hirose K, Koji Y, Hirayama Y, et al. Brachial-ankle pulse wave velocity as a marker of atherosclerotic vascular damage and cardiovascular risk. Hypertens Res. 2003;26:615-22.

18. Imanishi R, Seto S, Toda G, Yoshida M, Ohtsuru A, Koide $Y$, et al. High brachial-ankle pulse wave velocity is an independent predictor of the presence of coronary artery disease in men. Hypertens Res. 2004:27:71-8.

19. Yamashina A, Tomiyama H, Takeda K, Tsuda H, Arai T, Hirose K, et al. Validity, reproducibility, and clinical significance of noninvasive brachial-ankle pulse wave velocity measurement. Hypertens Res. 2002;25:359-64.

20. Lin WY, Lai MM, Li Cl, Lin CC, Li TC, Chen CC, et al. In addition to insulin resistance and obesity, brachial-ankle pulse wave velocity is strongly associated with metabolic syndrome in Chinese-a population-based study (Taichung Community Health Study, TCHS). J Atheroscler Thromb. 2009;16:105-12.

21. Lim S, Shin H, Song JH, Kwak SH, Kang SM, Won YJ, et al. Increasing prevalence of metabolic syndrome in Korea: the Korean National Health and Nutrition Examination Survey for 1998-2007. Diabetes Care. 2011;34:1323-8. 
22. Golden SH, Folsom AR, Coresh J, Sharrett AR, Szklo M, Brancati F. Risk factor groupings related to insulin resistance and their synergistic effects on subclinical atherosclerosis: the atherosclerosis risk in communities study. Diabetes. 2002:51:3069-76.

23. Sattar N, Gaw A, Scherbakova O, Ford I, O'Reilly DS, Haffner SM, et al. Metabolic syndrome with and without C-reactive protein as a predictor of coronary heart disease and diabetes in the West of Scotland Coronary Prevention Study. Circulation. 2003:108:414-9.

24. Won KB, Chang HJ, Kim HC, Jeon K, Lee H, Shin S, et al. Differential impact of metabolic syndrome on subclinical atherosclerosis according to the presence of diabetes. Cardiovasc Diabetol. 2013;12:41.

25. Williamson DF, Madans J, Anda RF, Kleinman JC, Giovino GA, Byers T. Smoking cessation and severity of weight gain in a national cohort. N Engl J Med. 1991:324:739-45.

26. Shimokata H, Muller DC, Andres R. Studies in the distribution of body fat. III. Effects of cigarette smoking. JAMA. 1989;261:1169-73.

27. Flegal KM, Troiano RP, Pamuk ER, Kuczmarski RJ, Campbell SM. The influence of smoking cessation on the prevalence of overweight in the United States. N Engl J Med. 1995;333:1165-70.

28. Huot I, Paradis G, Ledoux M. Factors associated with overweight and obesity in Quebec adults. Int J Obes Relat Metab Disord. 2004;28:766-74.

29. Molarius A, Seidell JC, Kuulasmaa K, Dobson AJ, Sans S. Smoking and relative body weight: an international perspective from the WHO MONICA Project. J Epidemiol Community Health. 1997;51:252-60.

30. Albanes D, Jones DY, Micozzi MS, Mattson ME. Associations between smoking and body weight in the U.S. population: analysis of NHANES II. Am J Public Health. 1987;77:439-44

31. Cicoira M, Maggioni AP, Latini R, Barlera S, Carretta E, Janosi A, et al. Body mass index, prognosis, and mode of death in chronic heart failure: results from the Valsartan Heart Failure Trial. Eur J Heart Fail. 2006:9:397-402.

32. Fonarow GC, Srikanthan P, Costanzo MR, Cintron GB, Lopatin M. An obesity paradox in acute heart failure: analysis of body mass index and inhospital mortality for 108,927 patients in the Acute Decompensated Heart Failure National Registry. Am Heart J. 2007;153:74-81.

33. Wu AH, Eagle KA, Montgomery DG, Kline-Rogers E, Hu YC, Aaronson KD. Relation of body mass index to mortality after development of heart failure due to acute coronary syndrome. Am J Cardiol. 2009;103:1736-40.

34. Won KB, Kim BK, Chang HJ, Shin DH, Kim JS, Ko YG, et al. Metabolic syndrome does not impact long-term survival in patients with acute myocardial infarction after successful percutaneous coronary intervention with drug-eluting stents. Catheter Cardiovasc Interv. 2014;83:713-20.

35. Simmons RK, Alberti KG, Gale EA, Colagiuri S, Tuomilehto J, Qiao Q, et al. The metabolic syndrome: useful concept or clinical tool? Report of a WHO expert consultation. Diabetologia. 2010;53:600-5.

36. Yoon KH, Lee JH, Kim JW, Cho JH, Choi YH, Ko SH, et al. Epidemic obesity and type 2 diabetes in Asia. Lancet. 2006:368:1681-8.

37. Shin CS, Lee HK, Koh CS, Kim Yl, Shin YS, Yoo KY, et al. Risk factors for the development of NIDDM in Yonchon County, Korea. Diabetes Care. 1997;20:1842-6.

38. Kim DJ, Lee MS, Kim KW, Lee MK. Insulin secretory dysfunction and insulin resistance in the pathogenesis of korean type 2 diabetes mellitus. Metabolism. 2001:50:590-3.

39. Charakida M, Jones A, Falaschetti E, Khan T, Finer N, Sattar N, et al, Childhood obesity and vascular phenotypes: a population study. J Am Coll Cardiol. 2012;60:2643-50

40. Corden B, Keenan NG, de Marvao AS, Dawes TJ, Decesare A, Diamond T, et al. Body fat is associated with reduced aortic stiffness until middle age. Hypertension. 2013;61:1322-7.

41. Lurbe E, Torro I, Garcia-Vicent C, Alvarez J, Fernández-Fornoso JA, Redon J. Blood pressure and obesity exert independent influences on pulse wave velocity in youth. Hypertension. 2012;60:550-5

42. Scuteri A, Cunha PG, Rosei EA, Badariere J, Bekaert S, Cockcroft JR, et al. Arterial stiffness and influences of the metabolic syndrome: a crosscountries study. Atherosclerosis. 2014;233:654-60.

43. Gurka MJ, Ice CL, Sun SS, Deboer MD. A confirmatory factor analysis of the metabolic syndrome in adolescents: an examination of sex and racial/ethnic differences. Cardiovasc Diabetol. 2012;11:128.

44. Herder M, Arntzen KA, Johnsen SH, Mathiesen EB. The metabolic syndrome and progression of carotid atherosclerosis over 13 years. The troms $\varnothing$ study Cardiovasc Diabetol. 2012;11:77.
45. Seo JY, Kim MK, Choi BY, Kim YM, Cho SI, Shin J. Elevated brachial-ankle pulse wave velocity is independently associated with microalbuminuria in a rural population. J Korean Med Sci. 2014;29:941-9.

46. Choi KM, Lee KW, Seo JA, Oh JH, Kim SG, Kim NH, et al. Relationship between brachial-ankle pulse wave velocity and cardiovascular risk factors of the metabolic syndrome. Diabetes Res Clin Pract. 2004;66:57-61.

doi:10.1186/1758-5996-7-3

Cite this article as: Won et al:: Inverse association between central obesity and arterial stiffness in Korean subjects with metabolic syndrome: a cross-sectional cohort study. Diabetology \& Metabolic Syndrome 2015 7:3.

\section{Submit your next manuscript to BioMed Central and take full advantage of:}

- Convenient online submission

- Thorough peer review

- No space constraints or color figure charges

- Immediate publication on acceptance

- Inclusion in PubMed, CAS, Scopus and Google Scholar

- Research which is freely available for redistribution

Submit your manuscript at www.biomedcentral.com/submit
C) BioMed Central 